\title{
NMDA Receptor-Dependent Synaptic Activation of TRPC Channels in Olfactory Bulb Granule Cells
}

\author{
Olga Stroh, ${ }^{1}$ Marc Freichel, ${ }^{2}$ Oliver Kretz, ${ }^{3}$ Lutz Birnbaumer, ${ }^{4}$ Jana Hartmann, ${ }^{5}$ and Veronica Egger ${ }^{1,6}$ \\ ${ }^{1}$ Physiological Institute, Ludwig Maximilians University, D-80336 Munich, Germany, ${ }^{2}$ Institute of Pharmacology and Toxicology, Saarland University, \\ D-66421 Homburg, Germany, ${ }^{3}$ Institute of Anatomy and Cell Biology, Department of Neuroanatomy, University of Freiburg, D-79104 Freiburg, Germany, \\ ${ }^{4}$ National Institute of Environmental Health Sciences, Research Triangle Park, North Carolina 27709, ${ }^{5}$ Institute for Neuroscience, Technical University of \\ Munich, D-80802 Munich, Germany, and ' Division of Neurobiology, Department of Biology II, Ludwig Maximilians University, D-82152 Martinsried, \\ Germany
}

Canonical transient receptor potential (TRPC) channels are widely expressed throughout the nervous system including the olfactory bulb where their function is largely unknown. Here, we describe their contribution to central synaptic processing at the reciprocal mitral and tufted cell-granule cell microcircuit, the most abundant synapse of the mammalian olfactory bulb. Suprathreshold activation of the synapse causes sodium action potentials in mouse granule cells and a subsequent long-lasting depolarization (LLD) linked to a global dendritic postsynaptic calcium signal recorded with two-photon laser-scanning microscopy. These signals are not observed after action potentials evoked by current injection in the same cells. The LLD persists in the presence of group I metabotropic glutamate receptor antagonists but is entirely absent from granule cells deficient for the NMDA receptor subunit NR1. Moreover, both depolarization and $\mathrm{Ca}^{2+}$ rise are sensitive to the blockade of NMDA receptors. The LLD and the accompanying $\mathrm{Ca}^{2+}$ rise are also absent in granule cells from mice deficient for both TRPC channel subtypes 1 and 4, whereas the deletion of either TRPC1 or TRPC4 results in only a partial reduction of the LLD. Recordings from mitral cells in the absence of both subunits reveal a reduction of asynchronous neurotransmitter release from the granule cells during recurrent inhibition. We conclude that TRPC1 and TRPC4 can be activated downstream of NMDA receptor activation and contribute to slow synaptic transmission in the olfactory bulb, including the calcium dynamics required for asynchronous release from the granule cell spine.

\section{Introduction}

The most abundant type of synaptic connection in the vertebrate olfactory bulb $(\mathrm{OB})$ is the reciprocal dendrodendritic synapse between the mitral/tufted cells (MTCs) and granule cells (GCs) where glutamate is released from the MTC dendrite onto the GC spine that in turn can release GABA. Sufficient excitation of GC dendrites results in the spread of inhibition to other MTCs. Thus, the synapse can mediate both recurrent and lateral inhibition of MTCs (for review, see Shepherd and Greer, 2004). Both types of inhibition show a prominent asynchronous component that lasts up to several $100 \mathrm{~ms}$ (Jahr and Nicoll, 1980; Isaacson and Strowbridge, 1998) and is probably located within the GC compartment of the reciprocal microcircuit (Chen et al., 2000), con-

Received July 20, 2011; revised Jan. 18, 2012; accepted Jan. 27, 2012.

Author contributions: M.F. and V.E. designed research; O.S., O.K., and V.E. performed research; M.F. and L.B. contributed unpublished reagents/analytic tools; 0.S., O.K., and V.E. analyzed data; J.H. and V.E. wrote the paper.

This work was supported by Deutsche Forschungsgemeinschaft Grants SFB 391 (O.S., V.E.), SFB 870 and SPP 1392 (V.E.), and SFB 530 (M.F.), and by NIH Intramural Research Program Grant Z01-ES-101684 (L.B.). We thank A. Schäfer, T. Kuner, and P. Seeburg for the GluR NR1 ${ }^{210 x}$ mice, V. Flockerzi for anti-TRPC1, anti-TRPC4, and anti-TRPC5 antibodies, B. Sutor and A. Konnerth for support, and I. Schneider, H. Jacobi, and R. Waberer for technical assistance. The authors declare no competing financial interests.

Correspondence should be addressed to Dr. Veronica Egger, Division of Neurobiology, Department of Biology II, Ludwig Maximilians University, Grosshadernerstrasse 2, D-82152 Martinsried, Germany. E-mail: v.egger@Imu.de. M. Freichel's present address: Institute of Pharmacology, Heidelberg University, D-69120 Heidelberg, Germany. DOI:10.1523/JNEUROSCI.3753-11.2012

Copyright $\odot 2012$ the authors $\quad 0270-6474 / 12 / 325737-10 \$ 15.00 / 0$ tained by large spines also known as gemmules. Possible mechanisms include an $I_{\mathrm{A}}$ current that delays GC spiking (Schoppa and Westbrook, 1999; Kapoor and Urban, 2006), and sluggish extrusion of $\mathrm{Ca}^{2+}$ from the gemmule (Egger and Stroh, 2009).

In addition, we have suggested that the nonselective cation current $I_{\text {CAN }}$ first identified in frog GCs (Hall and Delaney, 2002) may also promote asynchronous release (Egger, 2008). In both frog and rat GCs, this plateau current and the associated long-lasting depolarization (LLD) are supported by NMDA receptor (NMDAR) activation and blocked by both flufenamic acid and increased intracellular $\mathrm{Ca}^{2+}$ buffering. In the olfactory bulb, LLDs are present in many neuronal classes [e.g., an NMDAR-independent form in mitral cells (Carlson et al., 2000)]. In GCs, a slow global extra $\mathrm{Ca}^{2+}$ entry was directly correlated to the duration of the LLD and mediated by the persistent activation of T-type voltage-dependent $\mathrm{Ca}^{2+}$ currents (VDCCs) (Egger, 2008).

Several of these properties resemble that of slow synaptic currents mediated by transient receptor potential (canonical) (TRPC) channels that have been described recently elsewhere in the CNS (Amaral and Pozzo-Miller, 2007; Clapham, 2007; Fowler et al., 2007; Hartmann et al., 2008; Becker et al., 2009). The seven TRPC channels, one of six subfamilies of the TRP cation channel superfamily, are expressed in many cell types (for review, see Moran et al., 2004; Birnbaumer, 2009). In the nervous system, TRPCs were initially identified in sensory nerve endings 
and later found also in axons and dendrites of central neurons. Functionally, TRPCs have been mostly implicated in sensory transduction and neurite outgrowth and development with a role in synaptic transmission emerging only recently. For example, while TRPC2 has been identified to play a crucial role in pheromone detection in the vomeronasal system (for review, see Zufall et al., 2005), there is no functional data on TRPC action in the main olfactory bulb so far.

Here, we tested the hypothesis that a TRPC channel is the molecular correlate of $I_{\text {CAN }}$ in GCs, using electrophysiological recordings and two-photon laser-scanning microscopy of local $\mathrm{Ca}^{2+}$ signals in GCs of mice deficient for different subtypes of TRPC proteins. We demonstrate a direct involvement of TRPC channels in synaptic excitation in higher sensory processing and provide evidence for a novel, NMDAR-mediated mechanism of activation of TRPCs that also affects neurotransmitter release from GC dendrites.

\section{Materials and Methods}

Animals, slice preparation, and electrophysiology. TRPC1/TRPC4 doubleknock-out (TRPC1/4 DKO) mice were generated by breeding TRPC1 $^{-1-}$ (Dietrich et al., 2007) and TRPC4 ${ }^{-1-}$ mice (Freichel et al., 2001). To generate TRPC1/TRPC4/TRPC5 triple-knock-out mice (used as controls for immunohistochemistry), the DKO mice were bred with mice in which exon 4 of the TRPC5 gene was deleted (Xue et al., 2011). All TRPC-deficient mice were on a mixed $129 \mathrm{SvJ}$ genetic background. The mice with the GC-specific NR1-knock-out were the same as the ones used in the study by Abraham et al. (2010) (see their Methods for the generation of the mice, injection of the virus, and the visualization of infected GCs using two-photon imaging). Sagittal olfactory bulb brain slices (thickness, $250 \mu \mathrm{m}$ ) were prepared of WT and mutant mice of either sex (P16-P213, WT Bl6 and 129SvJ strain), in accordance with the European Commission Council directives for animal care. For the influence of age on the physiological readout, see Results. All experiments were performed at room temperature $\left(\sim 21^{\circ} \mathrm{C}\right)$. For all current-clamp experiments in GCs, the intracellular solution contained the following (in mM): $130 \mathrm{~K}$-methylsulfate, $10 \mathrm{HEPES}, 4 \mathrm{MgCl}_{2}, 4 \mathrm{Na}_{2} \mathrm{ATP}, 0.4$ NaGTP, 10 Na-phosphocreatine, 2 ascorbate, at pH 7.2, and in addition $100 \mu \mathrm{M}$ of the calcium-sensitive dye OGB-1 (Invitrogen) for imaging experiments. The extracellular ACSF was bubbled with carbogen and contained the following (in mM): $125 \mathrm{NaCl}, 26 \mathrm{NaHCO}_{3}, 1.25 \mathrm{NaH}_{2} \mathrm{PO}_{4}$, 20 glucose, $2.5 \mathrm{KCl}, 1 \mathrm{MgCl}_{2}$, and $2 \mathrm{CaCl}_{2}$. Pharmacological agents used were D-APV (25 $\mu \mathrm{M}$; Sigma-Aldrich), 6-amino- $N$-cyclohexyl- $N, 3$ dimethylthiazolo[3,2-a]benzimidazole-2-carboxamide (YM289189), and 2-methyl-6-(phenylethynyl)pyridine (MPEP) (10 and $40 \mu \mathrm{M}$; Tocris). For voltage-clamp experiments in mitral cells, the internal solution contained the following (in mM): 125 Cs-methylsulfate, 10 HEPES, 10 TEA, $4 \mathrm{MgCl}_{2}$, 2.5 $\mathrm{Na}_{2}$ ATP, 0.4 NaGTP, $10 \mathrm{Na}$-phosphocreatine, 2 ascorbate, $10 \mathrm{~mm}$ QX-314 at pH 7.2. The ACSF was the same as above, except for the omission of $\mathrm{MgCl}_{2}$. Cells were recorded from in whole-cell mode with an EPC-9 amplifier (HEKA).

Activation of the MTC input was achieved via glomerular stimulation (cf. Egger, 2008) using an STG-1004 stimulator (Multi Channel Systems). To ensure sufficient connectivity for suprathreshold stimulation, most patched GCs were located close to the mitral cell layer (i.e., superficially) and thus were likely to be connected to both mitral and tufted cells (Orona et al., 1983). Synaptic APs in GCs were evoked by glomerular stimulation [glomerular action potentials (glAPs)]; artificial APs [somatic action potentials (sAPs)] were evoked by brief somatic current injections $(1 \mathrm{~ms}, 1000 \mathrm{pA})$. The average resting potential was at $V_{\mathrm{m}}=-79 \pm 4 \mathrm{mV}(n=17)$. GCs were generally held at a potential of -70 to $-80 \mathrm{mV}$; cells that required $>50 \mathrm{pA}$ of holding current were not accepted.

For mitral cell recordings in voltage clamp, we used pipettes sized 4-6 $\mathrm{M} \Omega$ and achieved series resistances $R_{\mathrm{s}}$ of $<20 \mathrm{M} \Omega$. $R_{\mathrm{s}}$ was monitored during the experiments. Dendrodendritic recurrent inhibition (DDI) was elicited by depolarizing mitral cells from -70 to $0 \mathrm{mV}$ for
$20 \mathrm{~ms}$. To prevent rundown, DDI was measured only every $60-120 \mathrm{~s}$ and analyzed after its amplitude stabilized (usually $\sim 20$ min after break in).

A subset of GCs both in WT and TRPC1/4 DKO were also filled with biocytin and processsed and reconstructed using Neurolucida (MicroBrightField), as described previously (Lübke et al., 2000).

Two-photon imaging. Imaging was performed on an Fluoview 300 system (Olympus), with two-photon excitation at $800 \mathrm{~nm}$ provided by a Ti:sapphire solid-state laser system (Mai Tai; Spectra Physics).

Immunohistochemistry. Young adult WT and TRPC1/4/5 triple knockout mice were anesthetized and transcardially perfused with $4 \%$ PFA in $0.1 \mathrm{M}$ PB. Animals assigned to fine-structure analysis were perfused with a fixative containing $4 \%$ PFA and $0.05 \%$ glutaraldehyde in $0.1 \mathrm{M} \mathrm{PB}$. The olfactory bulbs were removed and cut coronally (section thickness, 50 $\mu \mathrm{m}$ ) on a vibratome, and the sections were stored in PB. For immunofluorescence labeling with rabbit anti-TRPC1, rabbit anti-TRPC4, or rabbit anti-TRPC5, respectively, sections were washed in $0.1 \mathrm{M} \mathrm{PB}$ and incubated in a blocking solution ( $5 \%$ normal goat serum, $2 \%$ bovine serum albumin, $0.1 \%$ Triton $\mathrm{X}$ in $\mathrm{PB}$ ) for unspecific protein binding sites for $60 \mathrm{~min}$. Sections were then incubated with the primary antibodies (final concentration, $0.5 \mu \mathrm{g} / \mu \mathrm{l}$ in blocking solution; overnight at $4^{\circ} \mathrm{C}$ ). Then, sections were washed in $\mathrm{PB}$ and incubated with secondary goat anti-rabbit antibody coupled to Cy3 for $45 \mathrm{~min}$ (1:600; Dianova) at room temperature. Finally, sections were washed in $\mathrm{PB}$, counterstained using DAPI (30 s; Hoechst), washed again in PB, and mounted for image analysis.

For electron microscopy, sections of the olfactory bulb sections were washed in PBS and cryoprotected in a solution containing 25\% sucrose and $10 \%$ glycerol in $50 \mathrm{~mm}$ PBS. The sections were freeze-thawed and incubated in blocking solution containing 5\% NGS in $0.1 \mathrm{~m} \mathrm{~PB}$ for $1 \mathrm{~h}$, followed by incubation with primary antibodies (final concentration, 2 $\mu \mathrm{g} / \mu \mathrm{l}$, for $24 \mathrm{~h}$ at $4^{\circ} \mathrm{C}$ ). After washing in phosphate buffer, the sections were incubated with biotinylated goat anti-rabbit secondary antibody (1:250; Vector Laboratories) for $4 \mathrm{~h}$ at room temperature, washed, and finally incubated for $1 \mathrm{~h}$ at room temperature with $\mathrm{ABC}$ solution (Vector Elite Kit; Vector Laboratories). Visualization of the antibody binding was performed using peroxidase reaction with DAB (diaminobenzidine) as the substrate. To exclude unspecific staining due to the secondary antibody, we performed negative controls using the same staining procedure except primary antibody incubation. After the sections were treated with $\mathrm{OsO}_{4}$, they were stained with uranyl acetate, dehydrated, and flatembedded in epoxy resin (Durcupan ACM; Fluka; Sigma-Aldrich). U1trathin sections were cut and analyzed with a Philips CM100 electron microscope.

Data analysis. Two-photon imaging data were analyzed as described previously (Egger, 2008). Changes in calcium were measured in terms of $\Delta F / F$ (Egger et al., 2005). Throughout the paper, $\tau_{1 / 2}$ denotes halfdurations from the peak amplitude of changes in $\Delta F / F$ or $V_{\mathrm{m}}$ onward, which were in the case of $V_{\mathrm{m}}$ measured between the onset of the LLD/ afterdepolarization (ADP) right after the sodium spike and one-half of its maximum amplitude. Both LLD amplitude and $\tau_{1 / 2}$ are often analyzed relative to the ADP following SAPs to eliminate variabilities that arise from the nonsynaptic component of the LLD (i.e., the ADP): the smaller the ratio, the stronger the synaptic contribution. The averaged dendrodendritic inhibition recorded in mitral cells was analyzed with respect to its $\tau_{1 / 2}$ and total charge after the stimulus artifact.

To assess statistical significance levels, the nonparametric Wilcoxon matched-pairs signed-ranks test was applied for comparing paired data sets (e.g., parameters of the sAP and glAP in the same cells), while the nonparametric Mann-Whitney test was used to compare unpaired data (e.g., the ADP half-duration in young vs adult animals). The entire set of data from WT, TRPC1 KO, TRPC4 KO, and TRPC1/4 KO animals presented in Figure $3 D$ was compared using the Kruskal-Wallis test; differences between individual data pairs were evaluated with the MannWhitney test followed by the appropriate Bonferroni-Holm correction. All averages are given \pm SD. 
A

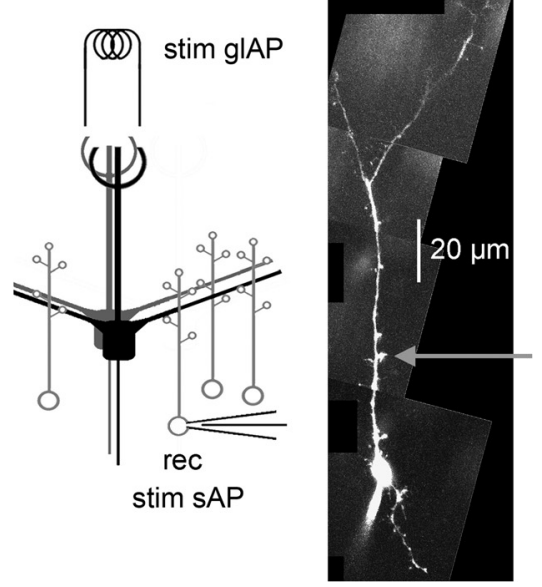

C
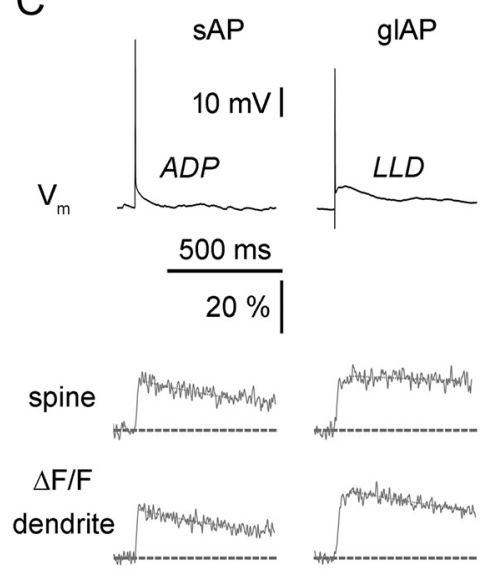
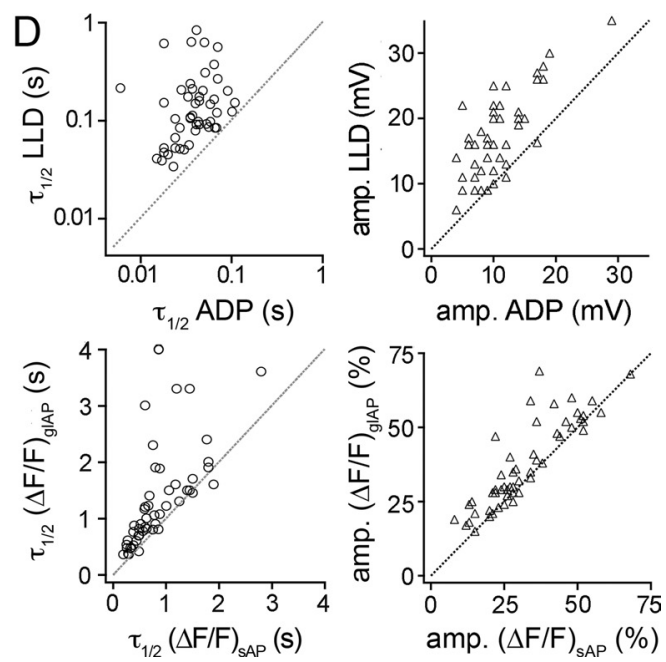

Figure 1. Synaptically evoked action potentials cause a plateau current in mouse granule cells. $A$, Scheme of recording configuration (Egger, 2008). Somatically evoked APs (sAP) are generated by current injection, synaptic APs by glomerular stimulation (gIAP). B, Two-photon scan of a wild-type mouse granule cell filled with $100 \mu \mathrm{m}$ 0GB-1. C, Data recorded from the cell in B. Top trace, Somatic voltage recording of an SAP and a gIAP. Note the time course of the ADP for the current-evoked signal versus the LLD for the synaptic signal. Bottom traces, Averaged fluorescence transients in response to the above APs recorded in a GC spine and its parent dendrite. $D$, Scatterplots of LLD versus ADP half-duration $\tau_{1 / 2}$ and amplitude (top; $n=49$ cells) and of the respective fluorescence signals $(\Delta F / F)_{\text {gIAP }}$ versus $(\Delta F / F)_{\text {sAP }}$ (bottom; $n=43$ dendrites and spines).

\section{Results}

\section{Synaptic spikes mediate long-lasting depolarization and} correlated $\mathrm{Ca}^{2+}$ entry in mouse GCs

To verify the presence of the synaptic plateau current $I_{\text {CAN }}$ in mouse GCs, we applied glomerular stimulation of MTC apical dendritic tufts (Schoppa et al., 1998) (Fig. 1A; 500-800 $\mu \mathrm{A}$ pulses, $100 \mu \mathrm{s}$ duration) in acute brain slices (P17-P132) while recording in wholecell current-clamp mode from GCs. This stimulation evoked EPSPs in GCs. Upon suprathreshold stimulation strength, the synaptic depolarization resulted in glAPs. Similar to our previous findings in rat, these glAPs were frequently followed by a LLD as shown in Figure $1 C$ (mean amplitude above resting potential, $17.7 \pm 6.4 \mathrm{mV}$; mean halfduration $\tau_{1 / 2}, 176 \pm 175 \mathrm{~ms} ; n=49$ GCs). The LLD was significantly larger and longer-lasting than the ADP following current-evoked sAPs in the same cells (by somatic injection of a 1000 pA step for 1 $\mathrm{ms}$ ), with a mean sAP-ADP amplitude above resting potential of $11.1 \pm 4.7 \mathrm{mV}$ and a mean half-duration $\tau_{1 / 2}$ of $42 \pm 22 \mathrm{~ms}(p<$ 0.001 for both; Fig. $1 D$ ). On average, the LLD lasted also considerably longer than the glomerular EPSP recorded just below the glomerular AP threshold in the same cell $\left(\tau_{1 / 2}, 166 \pm 174\right.$, vs $88 \pm 58$ $\mathrm{ms} ; n=39 ; p<0.001)$. Thus, the LLD is not just a barrage of EPSPs due to MTC-GC network activity; its generation most likely requires both synaptic input and $\mathrm{Na}^{+} \mathrm{AP}$.

The occurrence of the LLD did not depend on the age of the animals: upon averaging the LLD and ADP $\tau_{1 / 2}$ and amplitude data in three age groups of WT mice-young $(\mathrm{P} 16-\mathrm{P} 22 ; n=$ 32 ), juvenile (P32-P42; $n=6$ ), and adult (P66-P139; $n=$ 7) - we found that, although both amplitude and duration of the plateau decreased slightly with age, $I_{\text {CAN }}$ was activated in all three groups (all significance levels LLD vs ADP for both amplitudes and $\left.\tau_{1 / 2}: p<0.005\right)$. The average LLD $\tau_{1 / 2}$ was always significantly longer than the average EPSP $\tau_{1 / 2}$ just below threshold (P66-P139: $p<0.01$ ).

To verify that the LLD is also correlated to global $\mathrm{Ca}^{2+}$ entry, we used two-photon laser scan imaging to analyze $\mathrm{Ca}^{2+}$ entry into GCs at high spatial resolution. We found that the LLD is accompanied by extra, slow $\mathrm{Ca}^{2+}$ entry both in the dendrite and the large reciprocal GC spines similar to our previous findings in rat (Egger, 2008). Figure $1 C$ shows $\Delta F / F$ transients in a spine and its parent dendrite of a mouse GC. $(\Delta F / F)_{\text {glAP }}$ was found to decay significantly more slowly than $(\Delta F / F)_{\mathrm{sAP}}$ in the same locations $\left(\tau_{1 / 2}, 1200 \pm 800 \mathrm{~ms}\right.$, vs $750 \pm 460 \mathrm{~ms} ; n=40$ spines in 27 cells; $p<0.001$; Fig. $1 D)$. The amplitudes of $(\Delta F / F)_{\mathrm{glAP}}$ were as large or larger than of $(\Delta F / F)_{\text {sAP }}(39 \pm 15$ vs $33 \pm 14 \%$; amplitude ratio $\mathrm{glAP} / \mathrm{sAP}, 1.21 \pm 0.28 ; p<0.001)$. For both data sets, there were no significant differences between dendrites and spines, so in Figure $1 D$ all data are pooled ( $n=51$ locations).

\section{LLD requires GC NMDARs but not mGluRs}

In frog and rat GCs, the activation of the plateau current $I_{\text {CAN }}$ was found to require a cytosolic rise in $\left[\mathrm{Ca}^{2+}\right]$; synaptically evoked plateau currents were sensitive to NMDAR blockade (Hall and Delaney, 2002; Egger, 2008). Like in other species, mouse NMDARs already participate in basal MTC-GC synaptic transmission under near-resting conditions (Laaris et al., 2007; Abraham et al., 2010).

As shown in Figure 2, $A$ and $B$, application of $25 \mu \mathrm{M}$ D-APV markedly reduced the LLD half-duration and amplitude $(235 \pm 236$ vs $92 \pm 44 \mathrm{~ms} ; 20.8 \pm 8.1$ vs $15.6 \pm 6.8 \mathrm{mV} ; p<$ 0.002 for both; $n=15$ cells). As to the $\left[\mathrm{Ca}^{2+}\right]$ transients, APV made $(\Delta F / F)_{\text {glaP }}$ decay as quickly as $(\Delta F / F)_{\text {sAP }}$ and have the same amplitude $\left(\tau_{1 / 2}\right.$ ratio glAP/sAP, control, $2.26 \pm 1.10$, vs $\mathrm{APV}, 0.92 \pm 0.08 ; n=6 ; p<0.025$; amplitude ratio, control, $1.34 \pm 0.29$, vs APV, $1.06 \pm 0.12 ; n=7 ; p<0.025)$. There was no effect of APV on $(\Delta F / F)_{\text {sAP }}$ (mean amplitude, control, $28 \pm$ $8 \%$, vs APV, $26 \pm 10 \%)$.

Given that APV might exert presynaptic effects on MTC NMDA autoreceptors (Isaacson, 1999; Salin et al., 2001) or affect the efficiency of glomerular stimulation (but see Egger et al., 2005; Egger, 2008), we also tested for the existence of the LLD in GCs that were deficient for the essential NMDAR subunit NR1. The GC-specific deletion was achieved via viral expression of Cre recombinase in GCs of conditional GluN1 ${ }^{2 \text { lox }}$ animals (Abraham et al., 2010). In none of the GCs tested was there any indication of a plateau current. The mean glAP/sAP ratio was $0.97 \pm 0.10$ for the amplitude and $1.00 \pm 0.14$ for $\tau_{1 / 2}$ of the afterdepolarization (Fig. $2 C$ ), while the absolute sAP ADP amplitudes and $\tau_{1 / 2}$ were not significantly different from the WT values given above (NR1 

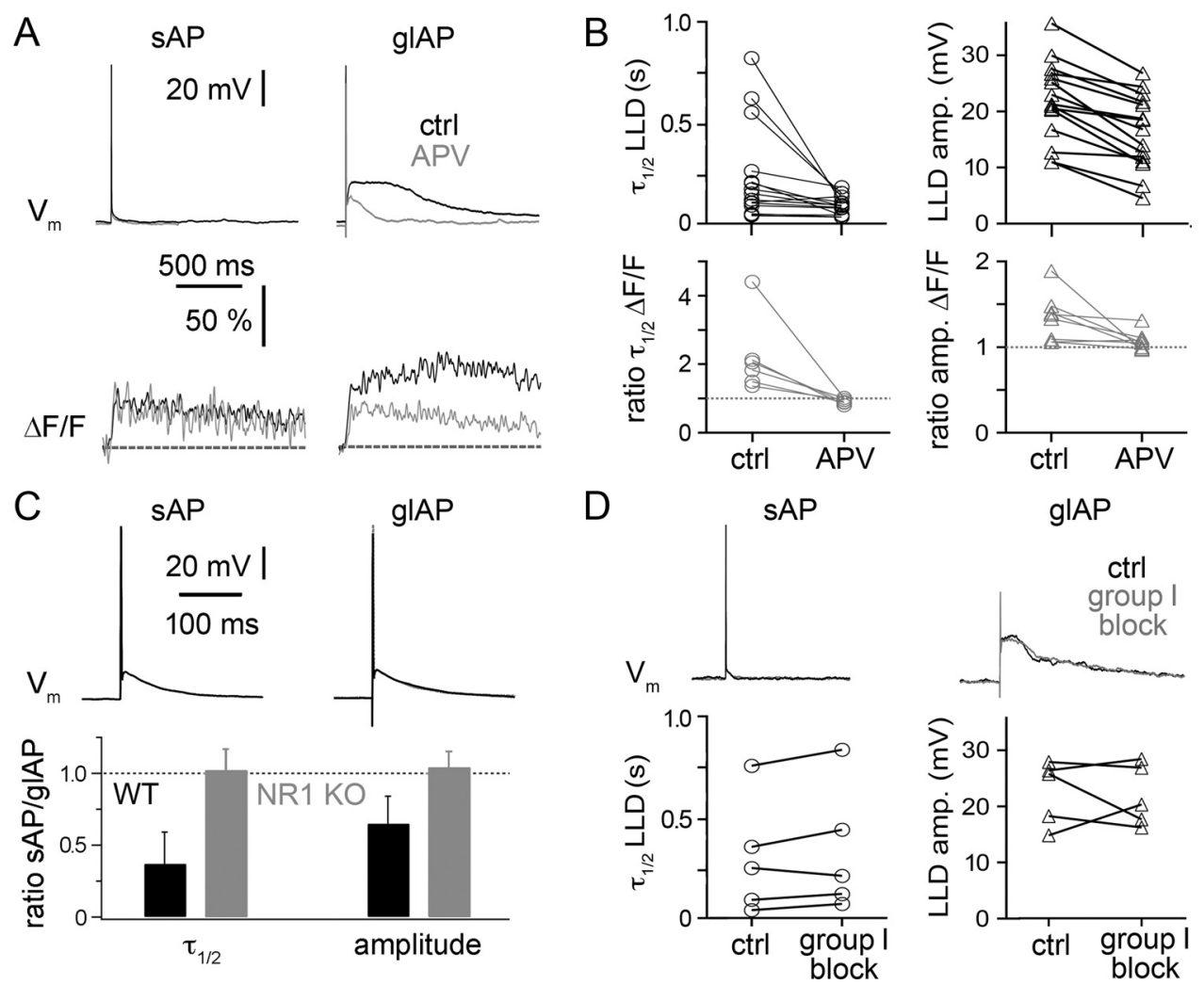

Figure 2. The synaptic plateau current is NMDAR dependent but does not require activation of group I mGluRs. $A$, Individual experiment showing sAP, glAP recorded at the soma and the respective $\Delta F / F$ at a dendritic location under control conditions (black traces) and in $25 \mu \mathrm{m} \mathrm{D}$-APV (gray traces). $\boldsymbol{B}$, All APV experiments: Effect of APV on LLD $\tau_{1 / 2}$ and amplitude ( $n=15$ cells) and ratios of $(\Delta F / F)_{\text {gIAP }}$ to $(\Delta F / F)_{\text {sAP }}$ for $\tau_{1 / 2}$ and amplitude $(n=6$ locations). C, Top, Individual recording from a granule cell deficient for NR1 (Abraham et al., 2010) showing sAP and glAP. The glAP trace (black) is shown in overlay of the SAP (gray). Bottom, Histogram plot of average ratios of SAP/gIAP ADP $\tau_{1 / 2}$ and amplitude of NR1-deficient GCS $(n=5)$ and WT GCS $(n=49)$. Error bars represent SD. D, Top, Individual experiment showing sAP, gIAP recorded at the soma under control conditions (black traces) and in the presence of $10 \mu \mathrm{M}$ YM289189 and $40 \mu \mathrm{m}$ MPEP (gray traces). Calibration is as in A. Bottom, All experiments with blockade of mGluR1/5: effect of blockers on LLD $\tau_{1 / 2}$ and amplitude ( $n=5$ cells).

KO: ADP amplitude, $13.0 \pm 5.6 \mathrm{mV}$; ADP_ $\tau_{1 / 2}, 29 \pm 19 \mathrm{~ms} ; n=$ 5 cells). Because MTCs were not infected, this experiment allows excluding any unspecific effects of NMDAR blockade on synapses other than those of GCs. Thus, the activation of NMDARs located in GCs is essential for the generation of the LLD and the concomitant $\mathrm{Ca}^{2+}$ entry.

Slow depolarizing currents such as $I_{\text {CAN }}$ have been associated with activation of G-protein-coupled receptors, in particular group I metabotropic receptors (Congar et al., 1997; Pace et al., 2007). So far, GCs are known to prominently express either mGluR5 or mGluR1, depending on their depth within the GC layer (GCL), and accordingly the application of group I agonists was found to increase GC excitability (for review, see Dong et al., 2009). To test for a role of group I mGluRs, we first recorded control responses, and then coapplied $10 \mu \mathrm{M}$ of the mGluR1 antagonist YM289189 and $40 \mu \mathrm{M}$ of the mGluR5 antagonist MPEP and recorded GC responses after at least 10 min of washin. This procedure has been reported to block mGluRs in acute brain slices (Fukunaga et al., 2007; Zheng and Raman, 2011). Figure $2 D$ shows that blockade of group I mGluRs did not decrease the LLD $\tau_{1 / 2}$ and amplitude (297 \pm 287 vs $336 \pm 315 \mathrm{~ms}$; $22.2 \pm 5.6$ vs $21.6 \pm 5.3 \mathrm{mV} ; n=5$ cells; compare with APV results above). Thus, group I mGluRs do not play an essential role in the generation of the LLD.

\section{TRPC channels mediate the LLD}

Another possible candidate for the mechanism underlying the plateau current is the activation of TRPC channels, because members of this channel family cause depolarization via their nonselective cation conductance and have been associated previously with plateau-like currents (Birnbaumer, 2009). TRPC4 is the most abundant TRPC in the olfactory bulb (Lein et al., 2007; Zechel et al., 2007). We confirmed the presence of TRPC4 protein in the GCL (Fig. $3 A a, b$ ) and the external plexiform layer (EPL) of the mouse $\mathrm{OB}$, also at the ultrastructural level (Fig. 4A-D) with anti-TRPC4 antibodies. Then we tested for the existence of an LLD in GCs of TRPC4-deficient mice $\left(\right.$ TRPC4 ${ }^{-1-}$ ) (Freichel et al., 2001). To render the graphical depiction more compact, the following data are presented in Figure $3 B-D$ as ratios of sAP to glAP afterdepolarization values. In the absence of TRPC4, the plateau current following the synaptic AP was reduced and, accordingly, the sAP/glAP-ADP $\tau_{1 / 2}$ ratio was significantly larger than in the WT $(0.64 \pm 0.16, n=14$, vs $0.38 \pm 0.23, n=$ $49 ; p<0.001$ for both), while the ADP ratios, the absolute mean ADP amplitude, and $\tau_{1 / 2}$ were similar in TRPC4 ${ }^{-1-}$ and WT ( $p>$ 0.05 for all). Thus, NMDAR-dependent plateau currents were significantly reduced but not completely absent in TRPC4 ${ }^{-1-}$ mice (compared with the NR1 deletion described above).

TRPC4 belongs to a subgroup of TRPC subunits with two other members-TRPC1 and TRPC5. All three readily associate with each other forming heteromeric channels (Strübing et al., 2001; Goel et al., 2002; Hofmann et al., 2002). Further immunohistochemistry with anti-TRPC1 antibodies confirmed the presence of TRPC1 protein in the GCL (Fig. 3Ac,d) and the EPL of the mouse $\mathrm{OB}$, also at the ultrastructural level (Fig. $4 E-H$ ). Expression of TRPC5 in GCs was not observed (data not shown). Thus, we hypothesized that the remaining LLD in the TRPC4 ${ }^{-1-}$ mice is carried 
A

TRPC4 AB
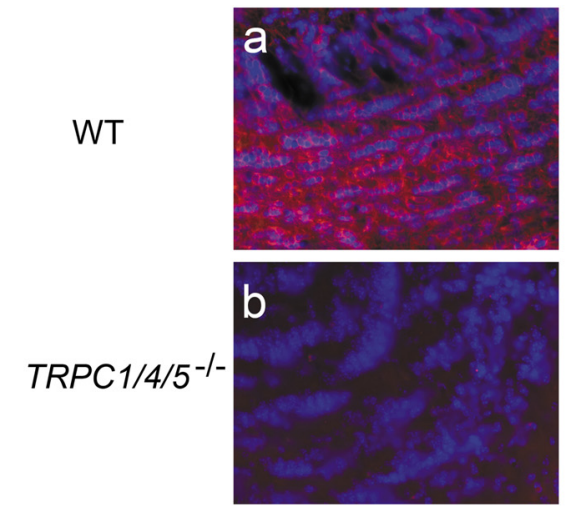

B

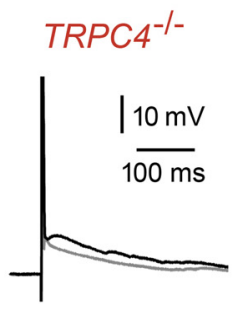

$\operatorname{TRPC} 1 / 4^{-/-}$
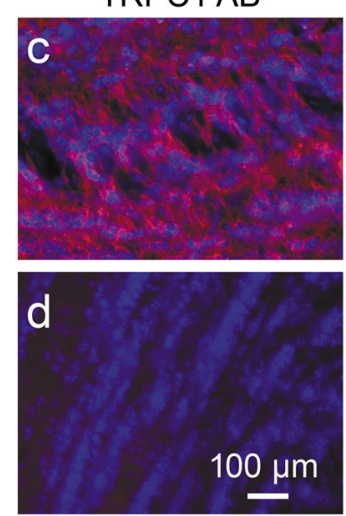

TRPC1 $^{-/-}$
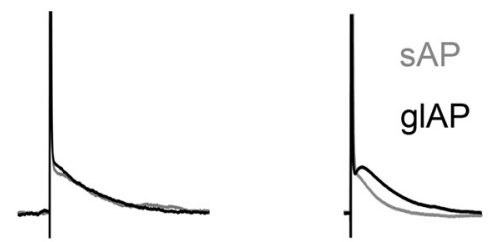

C
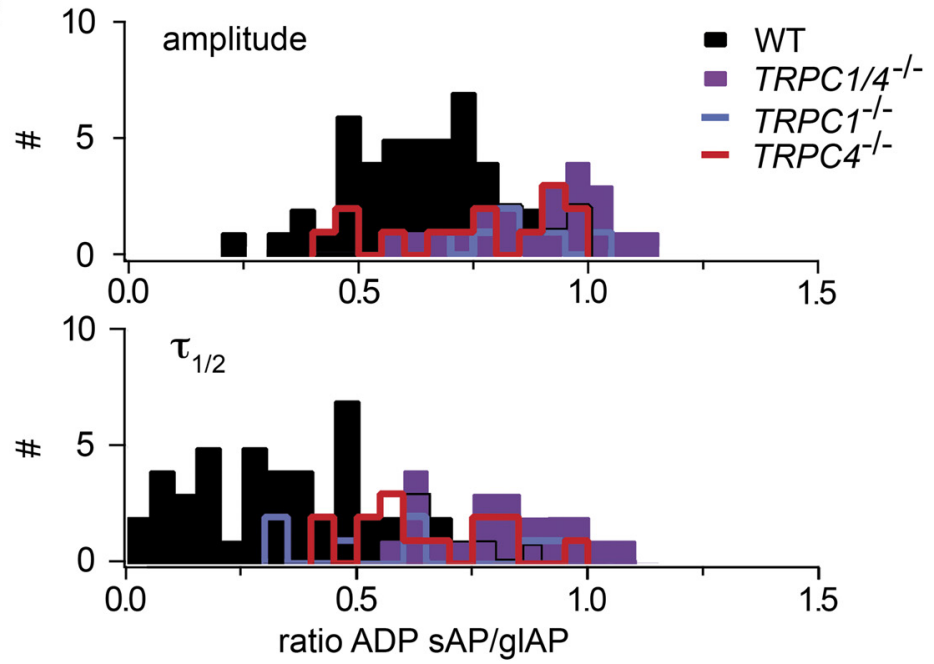

D

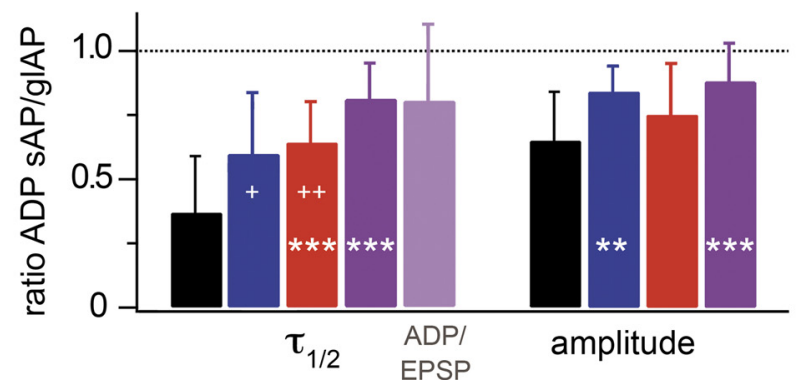

Figure 3. Presence of TRPC4 and TRPC 1 in GCs; TRPC4 deletion reduces the plateau, TRPC $1 / 4$ deletion blocks it. $A$, TRPC4 immunoreactivity is detectable in the olfactory GCL in WT mice (a; red) but not in TRPC1/4/5 triple KO (TKO) mice (b). TRPC1 immunoreactivity is strongly visible in the olfactory GCL in WT mice (c) but not in TRPC1/4/5 TKO mice (d). DAPI counterstain is in blue. Scale bar in $\boldsymbol{d}$ applies to all. $B$, Examples for weaker or missing LLDs in TRPC4 ${ }^{-1-}$, TRPC1/4DKO, and TRPC1 ${ }^{-1-}$ animals. Averaged traces are shown. C, Distributions of the ratios of SAP/gIAP ADP $\tau_{1 / 2}$ and amplitude for WT and the three different deletions. WT, Black columns; $\operatorname{TRPC1}^{-/-}$, red line; $\operatorname{TRPC} 4^{-1-}$, blue line; TRPC1/4 DKO, purple columns. Indication of overlap regions of WT and DKO distributions via cityscape. D, Summary of the average ratios for all four conditions. For the TRPC1/4 DKO, the ratio of the SAP-ADP versus the EPSP $\tau_{1 / 2}$ just below threshold is also shown. The total significance level for the difference between the most unequal values is $p<0.0001$ for both ratios (Kruskal-Wallis test). Significance levels of individual results in $\mathrm{KO}$ animals versus WT indicated on the respective bars with asterisks and of single $\mathrm{KO}$ animals versus DK0 with plus signs; ${ }^{+} p<0.05 ;{ }^{++, * *} p<0.02{ }^{* * *} p<0.001$; no symbol, not significant (pairwise Mann-Whitney tests with Bonferroni-Holm correction). Error bars represent SD. by TRPC1. Indeed, in mice deficient for both TRPC1 and TRPC4 (TRPC1/4 DKO), the plateau currents were almost completely absent (Fig. 3B-D). Here, both the amplitude and $\tau_{1 / 2}$ ratios were significantly different from the WT ( $n=21$ vs $n=49 ; p<$ 0.001 for both), whereas the absolute sAPADP amplitude and $\tau_{1 / 2}$ were unaltered in the TRPC1/4 DKO animals compared with WT mice ( $p>0.05$ for both). The remaining small difference between sAP- and glAPafter depolarizations is explained by the EPSP underlying the glAP: the $\tau_{1 / 2}$ values of the EPSP just below threshold and the glAP-afterdepolarization were similar in the TRPC1/4 DKO $(71 \pm 54$ vs $69 \pm 38 \mathrm{~ms} ; n=$ 21 ); accordingly, the $\tau_{1 / 2}$ ratio of sAP-ADP/ EPSP is the same as for sAP-ADP/glAPADP (Fig. 3D). Moreover, the EPSP $\tau_{1 / 2}$ values were not significantly different between TRPC1/4 DKO and WT $(p=0.40)$, reinforcing the notion that EPSPs alone do not suffice to generate the LLD.

Our finding that both TRPC4 and TRPC1 contribute to the long-lasting synaptic signals in OB GCs was corroborated by results obtained in TRPC1 ${ }^{-1-}$ mice ( $n=7$ GCs; Fig. $3 B-D)$. In summary, the deletion of either TRPC1 or TRPC4 caused significantly smaller effects on the plateau current $\tau_{1 / 2}$ ratios than the deletion of both genes (TRPC1 ${ }^{-1-}$ vs $\mathrm{DKO}, p<0.05$, and TRPC4 ${ }^{-/-}$vs DKO, $p<$ 0.02 ; statistical significances for $\mathrm{ADP}$ ratio comparisons between different mouse lines evaluated by Kruskal-Wallis test followed by pairwise Mann-Whitney test with appropriate Bonferrroni-Holm correction).

We then tested whether the extra $\mathrm{Ca}^{2+}$ entry associated with the plateau was also abolished in the TRPC1/4 DKO animals, using two-photon laser-scanning microscopy. Indeed, the amplitudes and halfdurations of $(\Delta F / F)_{\text {glAP }}$ and $(\Delta F / F)_{\text {sAP }}$ were equal in the DKO GCs $(36 \pm 13$ vs $35 \pm 14 \%$ and $580 \pm 380$ vs $590 \pm 340 \mathrm{~ms}$; $n=28$ locations in 11 cells; both $p>0.1$; Fig. $5 B, C)$. Accordingly, both the amplitude and $\tau_{1 / 2}$ ratios of $(\Delta F / F)_{\mathrm{sAP}}$ to $(\Delta F /$ $F)_{\text {glAP }}$ were significantly larger than in the WT $(p<0.001)$, and not significantly different from $1(0.97 \pm 0.08$ and $1.04 \pm$ $0.20, p>0.25$, single-sample $t$ test). Thus, NMDAR-dependent extra $\mathrm{Ca}^{2+}$ entry evoked by suprathreshold synaptic input is absent in TRPC1/4 DKO mice.

\section{Deletion of TRPC1 and TRPC4 does not reduce excitability}

The general deletion of both TRPC1 and TRPC4 could indirectly impede the LLD generation by detrimental effects on the neuronal excitability of MTCs and GCs (Cvetkovic-Lopes et al., 2010). The afore- 

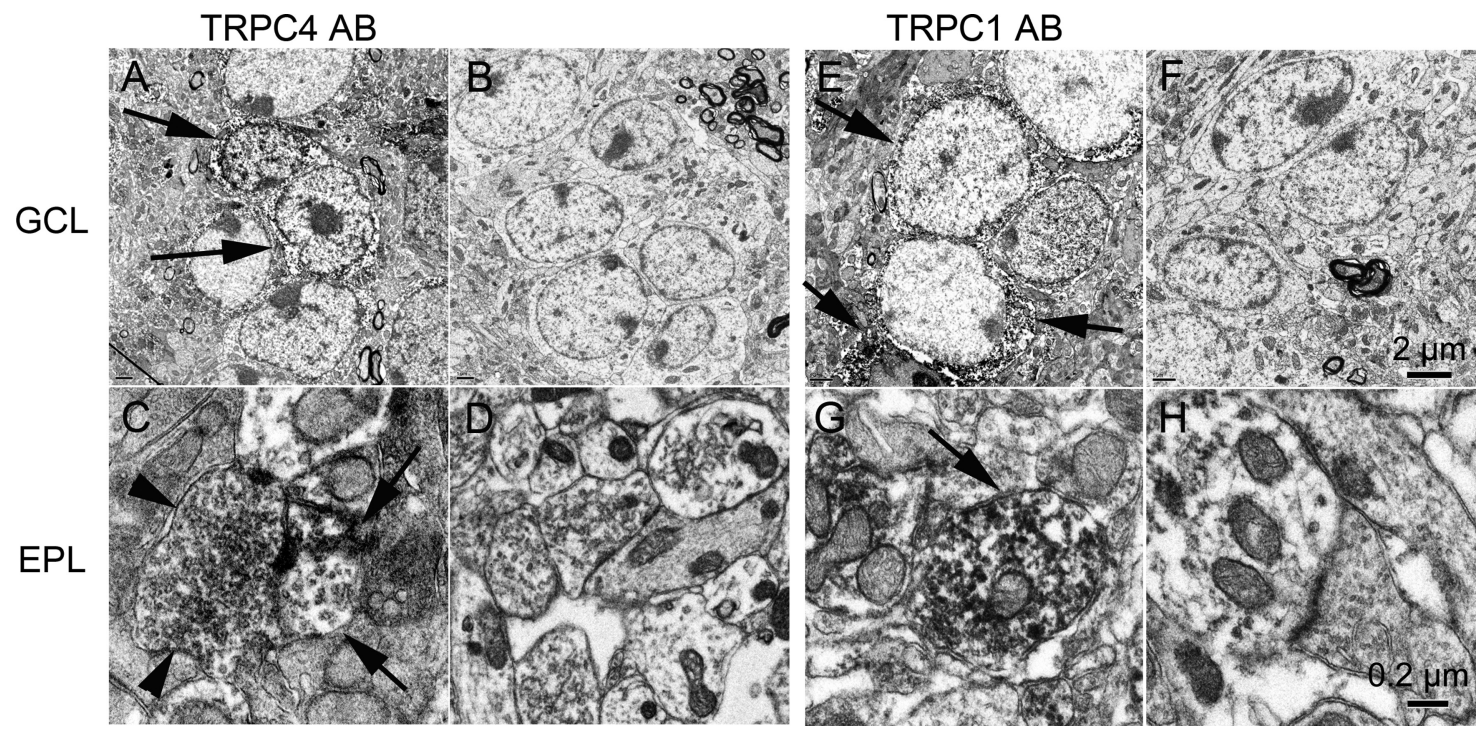

Figure 4. TRPC4 and TRPC1 are present in granule cell somata and synapses in the external plexiform layer at the ultrastructural level. Ultrastructural analysis using preembedding diaminobenzidine labeling for TRPC4 revealed a strong labeling of the granule cell somata (arrows) in WT mice $(\boldsymbol{A})$, but not in controls lacking primary antibody incubation $(\boldsymbol{B})$. In higher magnifications of the EPL, many immunopositive presynaptic (arrowheads) and postsynaptic (arrows) profiles are detectable in WT (C), but not in controls (D). A similar analysis for TRPC1 revealed a strong labeling of the granule cell somata (arrows) in WT mice $(\boldsymbol{E})$, but not in controls lacking primary antibody incubation $(\boldsymbol{F})$. In higher magnifications of the EPL, many immunopositive dendrites are detectable in WT $(G)$, but not in controls $(\boldsymbol{H})$.

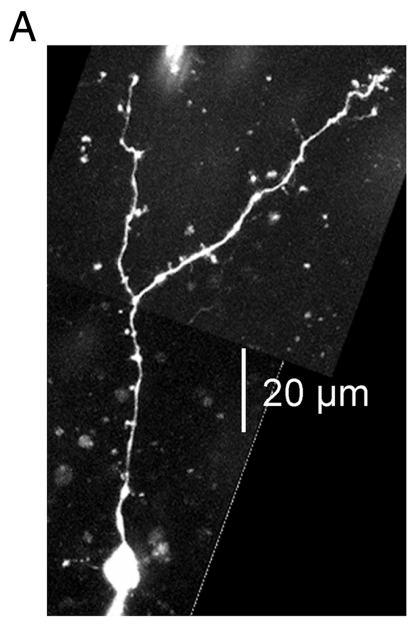

B

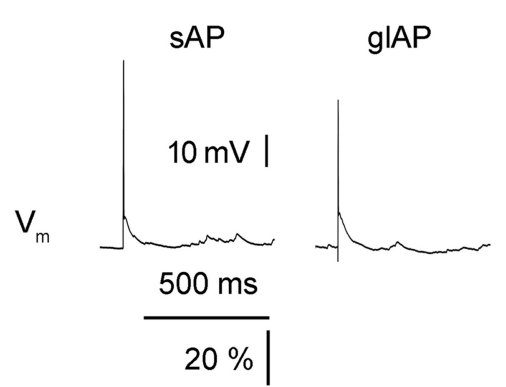

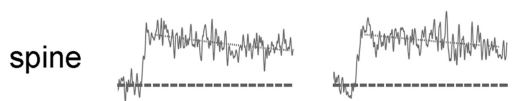

$\Delta \mathrm{F} / \mathrm{F}$

dendrite
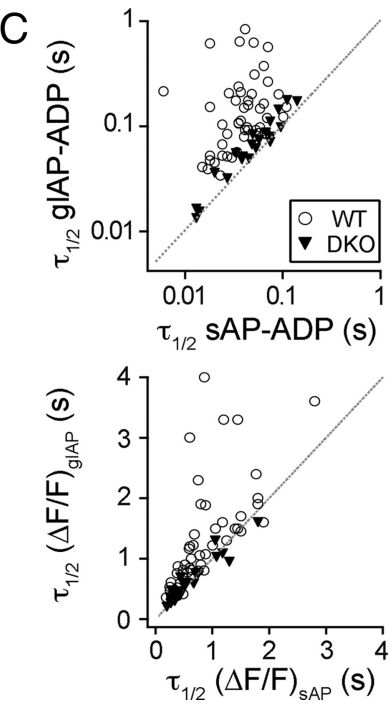
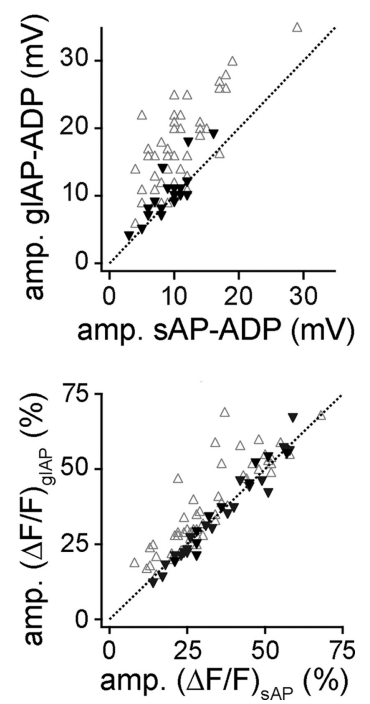

Figure 5. The extra $\mathrm{Ca}^{2+}$ signal is absent from TRPC1/4DKO GCS. A, Two-photon scan of a representative TRPC1/4 DKO granule cell. B, Analogous to Figure $1 C$, but data from TRPC1/4 DKO granule cell. Note the similarity of the responses compared with Figure 1 C. C, Scatterplots of glAP-ADP versus sAP-ADP $\tau_{1 / 2}$ and amplitudes and $(\Delta F / F)_{\text {glAP }}$ versus $(\Delta F / F)_{\text {sAP }} \tau_{1 / 2}$ and amplitudes, respectively. The plots show both TRPC1/4 DKO data (black inverted triangles) and WT data (open symbols, as in Fig. 1) to facilitate comparison (WT, $n=43$ dendrites and spines; TRPC1/4 DK0, $n=$ 28 dendrites and spines).

mentioned immunohistochemistry with anti-TRPC1 and anti-TRPC4 antibodies yielded no evidence for the presence of any of the two proteins in olfactory receptor neuron axons. Mitral cells expressed both TRPC1 and TRPC4, while tufted cells showed only expression of TRPC1 (data not shown). Thus, we investigated effects of the TRPC1/4 double deletion on synaptic transmission between MTCs and GCs and also GC excitability per se.

As to the shape of the $\mathrm{GC} \mathrm{Na}^{+}$AP in WT and DKO animals, both amplitude and width did not show any significant differences (for absolute data and $p$ levels of this section, see Table 1). The frequency of APs in response to a depolarizing current pulse at $50 \mathrm{pA}$ and $800 \mathrm{~ms}$ duration did also not differ significantly between the two populations. The frequency was evaluated for cells responding at this current amplitude; the fraction of silent cells was 0.35 in the WT and 0.39 in the DKO. The input resistance of the two groups was similar. Also, the average extracellular stimulation threshold for the generation of synaptic APs was equal, and as stated above, the EPSP $\tau_{1 / 2}$ just below AP threshold was the same for both. We also tested for possible effects of the TRPC1/4 DKO on GC morphology (see Materials and Methods) but did not observe any major changes with respect to the total length of the apical dendrite as well as to the number of its branchpoints. 
Table 1. Excitability and morphology of TRPC1/4 DKO granule cells versus WT granule cells

\begin{tabular}{|c|c|c|c|c|c|}
\hline \multirow[b]{2}{*}{ Parameter } & \multicolumn{2}{|l|}{ WT } & \multicolumn{2}{|l|}{ TRPC1/4 DKO } & \multirow{2}{*}{$\begin{array}{l}p \text { (Mann- } \\
\text { Whitney } \\
\text { test) }\end{array}$} \\
\hline & $\begin{array}{l}\text { Mean } \\
\text { value } \pm \text { SD }\end{array}$ & $n$ & $\begin{array}{l}\text { Mean } \\
\text { value } \pm \text { SD }\end{array}$ & $n$ & \\
\hline $\begin{array}{l}\text { Input resistance } \\
\text { SAP }\end{array}$ & $1.07 \pm 0.39 \mathrm{G} \Omega$ & 20 & $0.89 \pm 0.44 \mathrm{G} \Omega$ & 19 & 0.14 \\
\hline $\mathrm{Na}^{+}$spike amplitude & $105 \pm 10 \mathrm{mV}$ & 35 & $111 \pm 16 \mathrm{mV}$ & 20 & 0.08 \\
\hline $\begin{array}{l}\mathrm{Na}^{+} \text {spike half-width } \\
\text { Number of APs at } 50 \mathrm{pA} \text {, }\end{array}$ & $1.9 \pm 0.4 \mathrm{~ms}$ & 18 & $2.1 \pm 0.4 \mathrm{~ms}$ & 19 & 0.11 \\
\hline $\begin{array}{c}800 \mathrm{~ms} \\
\text { Synaptic input }\end{array}$ & $8.8 \pm 3.7$ & 30 & $7.7 \pm 3.8$ & 14 & 0.24 \\
\hline $\begin{array}{l}\text { Extracellular stimulation } \\
\text { threshold }\end{array}$ & $620 \pm 420 \mu \mathrm{A}$ & 35 & $620 \pm 380 \mu \mathrm{A}$ & 23 & 0.33 \\
\hline $\begin{array}{l}\text { Just subthreshold EPSP } \tau_{1 / 2} \\
\text { Morphology of apical dendrite }\end{array}$ & $88 \pm 58 \mathrm{~ms}$ & $\begin{array}{l}39 \\
25\end{array}$ & $71 \pm 54 \mathrm{~ms}$ & 21 & 0.40 \\
\hline $\begin{array}{l}\text { Morphology of apical dendrite } \\
\text { Length }\end{array}$ & $240 \pm 150 \mu \mathrm{m}$ & 25 & $215 \pm 110 \mu \mathrm{m}$ & 9 & 0.67 \\
\hline Number of branchpoints & $2.6 \pm 1.1$ & & $2.0 \pm 1.7$ & & 0.24 \\
\hline
\end{tabular}

While more subtle effects cannot be excluded, these data speak against a major alteration of GC excitability and MTC-to-GC synaptic transmission in the absence of TRPC1/4.

\section{TRPCs promote slow feedback inhibition of mitral/tufted cells}

The MTC-GC microcircuit can provide recurrent inhibition of MTCs via dendritic release of GABA from the reciprocal GC spine. This release occurs in part asynchronously (see Introduction). A role for TRPC4 in dendritic release has been previously demonstrated in thalamic GABAergic neurons (Munsch et al., 2003). Because in GCs TRPC activation via MTC input results in slow extra $\mathrm{Ca}^{2+}$ entry, we hypothesized that the slow TRPCmediated plateau current facilitates recurrent dendrodendritic inhibition of MTCs.

To measure recurrent inhibition, we voltage clamped mitral cells and applied brief depolarizing pulses that are known to activate the microcircuit and cause recurrent GABA release (Jahr and Nicoll, 1980; Isaacson and Strowbridge, 1998). To reduce voltage escape, QX-314 was included in the pipette solution, and NMDAR activation was facilitated by omitting $\mathrm{Mg}^{2+}$ from the ACSF (Isaacson and Strowbridge, 1998; Schoppa et al., 1998; Chen et al., 2000; Halabisky et al., 2000). Figure 6 illustrates that the decay kinetics of the resulting barrage of IPSCs was significantly faster in the TRPC1/4 DKO than in the WT mice $\left(\tau_{1 / 2}\right.$ DKO, $70 \pm 30 \mathrm{~ms}, n=8$ cells, vs WT, $280 \pm 140 \mathrm{~ms}, n=7$ cells; $p<0.005)$. The amplitudes across these experiments were highly variable, probably because of the differing connectivity in acute slices, but not significantly different between the two populations. There was no correlation between the amplitudes and the half-durations (WT, $r=-0.27$; DKO, $r=-0.31$ ). However, the integrals of the responses were larger in the WT $(143 \pm 115 \mathrm{nA}$ $\mathrm{ms})$ than in the DKO (43 $\pm 27 \mathrm{nA} \mathrm{ms} ; p<0.025)$. Thus, we conclude that TRPC-mediated $\mathrm{Ca}^{2+}$ entry contributes to dendritic GABA release from the GC spine and fosters in particular late/asynchronous recurrent inhibition.

\section{Discussion}

\section{TRPC activation cascade}

We have demonstrated that TRPC1 and TRPC4 are required for a synaptic, $I_{\mathrm{CAN}}$-mediated plateau current at the MTC-GC synapse. This conclusion is based on the absence of plateau currents at this synapse in the combined deletion of TRPC1 and TRPC4, while individual deletion of either TRPC1 or TRPC4 is accompa-

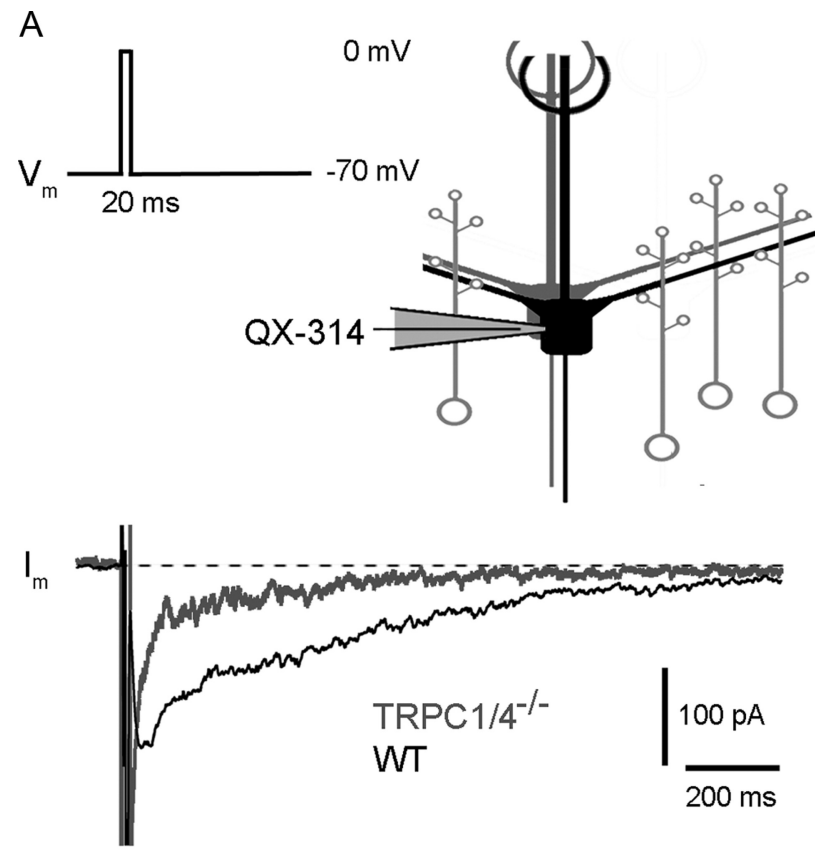

B

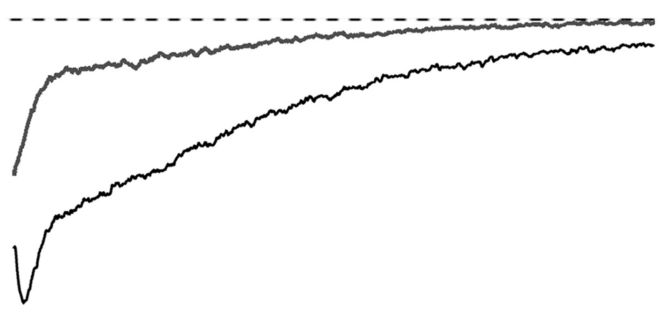

Figure 6. TRPC channels promote recurrent dendrodendritic inhibition of mitral cells. $\boldsymbol{A}$ Scheme of experiment and recordings of reciprocal DDI in a WT mouse (black) and a TRPC1/4 DKO mouse (gray) mitral cell. $\boldsymbol{B}$, Averaged DDI recordings for all experiments ( $n=7$ WT and $n=8$ DKO cells). Both the averaged $\tau_{1 / 2}$ and integral show a significant decrease for the TRPC1/4 DKO versus WT ( $p<0.005$ and $p<0.025)$.

nied by partial reductions in the plateau current amplitude and duration. We find that synaptic activation of TRPC1/4 is achieved via NMDA receptor-mediated signaling.

Although TRPC channels are regulated by intracellular $\mathrm{Ca}^{2+} /$ calmodulin (for review, see Zhu, 2005), so far their activation was found to critically depend on $\mathrm{G}_{\mathrm{q}}$-protein-coupled receptors in other examples of neuronal TRPC action: In cerebellar Purkinje cells, an mGluR1-dependent slow EPSP has been shown to be mediated by TRPC3 (Hartmann et al., 2008). Activation of a TRPC channel downstream of synaptic activation of mGluR1 has been suggested also for hippocampal oriens/alveus interneurons (Topolnik et al., 2006) and CA1 pyramidal cells (El-Hassar et al., 2011). In the amygdala, synaptic responses downstream of mGluR1 and the cholecystokinin-2 receptor are significantly reduced in TRPC5 $5^{-1-}$ mice (Riccio et al., 2009). In a heterologous expression system, mGluR1 is able to couple to TRPC1 (Kim et al., 2003).

The dependence of TRPC channel opening on the activation of an ionotropic glutamate receptor has not been described before. Current views hold that TRPC channels are activated by phospholipase C (PLC)-coupled metabotropic receptors (Soboloff et al., 2007). Consistent with that, a group I mGluR-specific agonistevoked inward current was recorded in OB GCs (Heinbockel et al., 2007). In addition, muscarinic acetylcholine receptors at the MTC-GC synapse were found to be coupled to a flufenamic acid- 
sensitive $I_{\text {CAN }}$ in GCs (Pressler et al., 2007; Ghatpande and Gelperin, 2009), similarly to neurons in the entorhinal cortex (Zhang et al., 2011). However, the lack of an effect of group I mGluR blockade on the GC LLD, the blockade of the LLD by APV, the triggering of the LLD by single stimulation - versus the repetitive stimulation that is often required to activate mGluRs - and the fact that ryanodine receptors but not $\mathrm{IP}_{3}$ receptors contribute to basal synaptic $\mathrm{Ca}^{2+}$ signaling in GC spines (Egger et al., 2005) rule out an essential involvement of metabotropic receptors in the type of synaptic response that we investigate here.

An mGluR-independent PLC activation following glutamate binding to NMDARs was observed in hippocampal neurons (Codazzi et al., 2006; Horne and Dell'Acqua, 2007). This effect is mediated by PLC $\delta$ isoforms (Codazzi et al., 2006) that are not controlled by $\mathrm{G}_{\mathrm{q}}$ but directly activated by $\mathrm{Ca}^{2+}$ (Allen et al., 1997). We have shown previously that NMDARs contribute a significant fraction to postsynaptic calcium signals at the reciprocal MTC-GC synapse (Egger et al., 2005). $\mathrm{Ca}^{2+}$ influx through the NMDAR channel is of crucial importance for the LLD in OB granule cells (Hall and Delaney, 2002; Egger, 2008), and PLC $\delta$ isoforms are expressed in the GC layer (Lein et al., 2007). It remains to be elucidated whether NMDAR-mediated $\Delta\left[\mathrm{Ca}^{2+}\right]_{\mathrm{i}}$ acts onto the TRPCs via PLC $\delta$ or whether the signaling pathway involves other steps. For TRPC3 in cerebellar Purkinje cells, a PLC-independent gating mechanism relies on the small GTPbinding protein Rho and subsequent phospholipase D activation (Glitsch, 2010). TRPC channels are known to be redundantly activated and appear to be located at a point of intersection of diverse signaling pathways (for review, see Hartmann et al., 2011). Moreover, TRPC channels in neurons are part of multiprotein postsynaptic signaling complexes that also contain neurotransmitter receptors, including the NMDAR (for review, see Ambudkar et al., 2006). For example, the cholesterol-binding protein caveolin-1 can scaffold NMDARs and Src protein kinases (Head et al., 2008) and attach TRPC subunits to the plasma membrane (Lockwich et al., 2000; Brazer et al., 2003). Src protein kinases, in turn, have been shown to activate both TRPC1 (Gervásio et al., 2008) and TRPC4 (Odell et al., 2005). At the MTC-GC synapse, the absence of synaptic plateau currents in the NR1-KO GCs argues against an activation of TRPCs via ryanodine receptors.

Since the coincidence of NMDAR activation and $\mathrm{Na}^{+}$spike is required to activate the TRPCs, we suggest that the relevant signal cascade is triggered by the elevation of $\left[\mathrm{Ca}^{2+}\right]_{\mathrm{i}}$ via NMDARs only if this elevation is enhanced by the membrane depolarization provided by the $\mathrm{Na}^{+}$spike, either via additional relief of the $\mathrm{Mg}^{2+}$ block or via activation of VDCCs, just as in classical coincidence detection mechanisms that play a role in synaptic plasticity (Blair et al., 2001).

Finally, it has been debated whether TRPC1 on its own can be a pore-forming subunit (for review, see Wu et al., 2010). We still find a plateau current (albeit reduced) in the absence of TRPC4, which is most likely mediated by TRPC1. Thus, apparently TRPC1 homomultimers can conduct currents in olfactory bulb GCs.

\section{Functional roles of TRPC activation}

TRPC activation results in a global $\mathrm{Ca}^{2+}$ entry in dendrites and spines of the GC that is due to T-type $\mathrm{Ca}^{2+}$ channel activation caused by the depolarizing plateau current (Egger, 2008). This prolonged $\mathrm{Ca}^{2+}$ entry persists during the plateau current and thus may contribute to delayed dendritic release of GABA. Indeed, we show that recurrent inhibition is faster and involves less charge transfer in TRPC1/4 DKO animals. We propose that TRPC1 and TRPC4 are key players in the regulation of slow dendritic GABA release from
GCs, similar to the role of TRPC4 in thalamic interneurons (Munsch et al., 2003). Obviously, however, TRPCs are not the only effectors of slow output from this system, since asynchronous release also occurs in the presence of TTX (Isaacson and Strowbridge, 1998), is not fully blocked in the $\mathrm{DKO}$, and there are also other mechanisms providing prolonged $\mathrm{Ca}^{2+}$ entry such as delayed GC spiking (Schoppa and Westbrook, 1999; Kapoor and Urban, 2006) and sluggish extrusion of $\mathrm{Ca}^{2+}$ from the GC dendrite (Egger and Stroh, 2009).

How does TRPC1/4 action then shape odor processing in the olfactory bulb? An implicit answer to this question is provided by the study of Abraham et al. (2010), in which a GC-specific deletion of NR1 was achieved in $\sim 40 \%$ of all GCs of the OB (GluN1 $\left.{ }^{\Delta \mathrm{GCL}}\right)$. In these cells, the activation of TRPC1/4 is also blocked, as shown above by the lack of the LLD for glomerularly evoked action potentials. Accordingly, recurrent inhibition following trains of APs is also reduced in GluN1 ${ }^{\Delta \mathrm{GCL}}$ mice in vitro. Behavioral tests showed that in GluN1 ${ }^{\Delta \mathrm{GCL}}$ mice learning and memory are not affected, although the discrimination of highly similar odorants takes significantly more time than in WT mice. Thus, TRPC action could also be related to fine odor discrimination; it remains to be elucidated what aspect of the above observations is due to other actions of the NMDAR apart from downstream TRPC-mediated effects.

However, since a major part of TRPC action appears to happen on the slow temporal timescale and odor discrimination has been shown to occur rather fast, we would also expect other roles of TRPC to emerge. For example, TRPC action may couple to the prominent slow, respiration-coupled oscillations intrinsic to the olfactory bulb (Macrides and Chorover, 1972), possibly via their interaction with T-type VDCCs (T-channels). We have already proposed that GC T-channels are periodically inactivated by slow olfactory bulb oscillations and thus GC output is likely to be also periodically modulated (Egger et al., 2003). The TRPC channelmediated long-lasting depolarizations can activate T-channels and thus produce global $\mathrm{Ca}^{2+}$ entry (Egger, 2008) and participate in driving slow bulbar oscillations but may also contribute to the periodic inactivation of T-channels in the course of these persistent depolarizations.

In addition to its importance for recurrent inhibition, the TRPC-mediated mechanism of LLD demonstrated here might play a role in lateral inhibition of neighboring MTCs, again by giving rise to global extra $\mathrm{Ca}^{2+}$ entry. Lateral inhibition will usually co-occur with TRPC activation because the latter requires a $\mathrm{GC} \mathrm{Na}^{+}$spike. The spike will propagate along the GC dendrite and cause substantial $\mathrm{Ca}^{2+}$ entry at other reciprocal spines (Egger et al., 2003; Zelles et al., 2006) that is enhanced by the TRPC-mediated extra global $\mathrm{Ca}^{2+}$ entry. Lateral inhibition per se does not necessarily require a $\mathrm{Na}^{+}$spike (Isaacson and Strowbridge, 1998 ) but may also be triggered by a $\mathrm{Ca}^{2+}$ spike in GCs (Pinato and Midtgaard, 2003; Egger et al., 2005) that is probably not capable of activating TRPCs. Nevertheless, the efficiency and duration of lateral inhibition following a GC AP are very likely to be enhanced by TRPC1/4 action. Thus, even though $\mathrm{Ca}^{2+}$ entry via NMDARs may not couple directly to recurrent GABA release (Isaacson, 2001), NMDAR activation can contribute to recurrent and lateral inhibition via the TRPC-mediated pathway.

Finally, we have shown that, in GCs, $\mathrm{Na}^{+}$spikes evoked by current injection are not equivalent to $\mathrm{Na}^{+}$spikes evoked by synaptic mitral and tufted cell input because only the latter are capable of TRPC activation and produce a different spatiotemporal pattern of postsynaptic $\mathrm{Ca}^{2+}$ entry. This finding may contribute to the recent debate on the validity of paradigms used to determine spike-timingdependent plasticity (Lisman and Spruston, 2010). 


\section{References}

Abraham NM, Egger V, Shimshek DR, Renden R, Fukunaga I, Sprengel R, Seeburg PH, Klugmann M, Margrie TW, Schaefer AT, Kuner T (2010) Synaptic inhibition in the olfactory bulb accelerates odor discrimination in mice. Neuron 65:399-411.

Allen V, Swigart P, Cheung R, Cockcroft S, Katan M (1997) Regulation of inositol lipid-specific phospholipase cdelta by changes in $\mathrm{Ca}^{2+}$ ion concentrations. Biochem J 327:545-552.

Amaral MD, Pozzo-Miller L (2007) TRPC3 channels are necessary for brain-derived neurotrophic factor to activate a nonselective cationic current and to induce dendritic spine formation. J Neurosci 27:5179-5189.

Ambudkar IS, Bandyopadhyay BC, Liu X, Lockwich TP, Paria B, Ong HL (2006) Functional organization of TRPC- $\mathrm{Ca}^{2+}$ channels and regulation of calcium microdomains. Cell Calcium 40:495-504.

Becker EB, Oliver PL, Glitsch MD, Banks GT, Achilli F, Hardy A, Nolan PM, Fisher EM, Davies KE (2009) A point mutation in TRPC3 causes abnormal Purkinje cell development and cerebellar ataxia in moonwalker mice. Proc Natl Acad Sci U S A 106:6706-6711.

Birnbaumer L (2009) The TRPC class of ion channels: a critical review of their roles in slow, sustained increases in intracellular $\mathrm{Ca}^{2+}$ concentrations. Annu Rev Pharmacol Toxicol 49:395-426.

Blair HT, Schafe GE, Bauer EP, Rodrigues SM, LeDoux JE (2001) Synaptic plasticity in the lateral amygdala: a cellular hypothesis of fear conditioning. Learn Mem 8:229-242.

Brazer SC, Singh BB, Liu X, Swaim W, Ambudkar IS (2003) Caveolin-1 contributes to assembly of store-operated $\mathrm{Ca}^{2+}$ influx channels by regulating plasma membrane localization of TRPC1. J Biol Chem 278:27208-27215.

Carlson GC, Shipley MT, Keller A (2000) Long-lasting depolarizations in mitral cells of the rat olfactory bulb. J Neurosci 20:2011-2021.

Chen WR, Xiong W, Shepherd GM (2000) Analysis of relations between NMDA receptors and GABA release at olfactory bulb reciprocal synapses. Neuron 25:625-633.

Clapham DE (2007) SnapShot: mammalian TRP channels. Cell 129:220.

Codazzi F, Di Cesare A, Chiulli N, Albanese A, Meyer T, Zacchetti D, Grohovaz F (2006) Synergistic control of protein kinase C $\gamma$ activity by ionotropic and metabotropic glutamate receptor inputs in hippocampal neurons. J Neurosci 26:3404-3411.

Congar P, Leinekugel X, Ben-Ari Y, Crépel V (1997) A long-lasting calciumactivated nonselective cationic current is generated by synaptic stimulation or exogenous activation of group I metabotropic glutamate receptors in CA1 pyramidal neurons. J Neurosci 17:5366-5379.

Cvetkovic-Lopes V, Eggermann E, Uschakov A, Grivel J, Bayer L, Jones BE, Serafin M, Mühlethaler M (2010) Rat hypocretin/orexin neurons are maintained in a depolarized state by TRPC channels. PLoS One 5:e15673.

Dietrich A, Kalwa H, Storch U, Mederos y Schnitzler M, Salanova B, Pinkenburg O, Dubrovska G, Essin K, Gollasch M, Birnbaumer L, Gudermann T (2007) Pressure-induced and store-operated cation influx in vascular smooth muscle cells is independent of TRPC1. Pflugers Arch 455:465-477.

Dong HW, Heinbockel T, Hamilton KA, Hayar A, Ennis M (2009) Metabotropic glutamate receptors and dendrodendritic synapses in the main olfactory bulb. Ann N Y Acad Sci 1170:224-238.

Egger V (2008) Synaptic sodium spikes trigger long-lasting depolarizations and slow calcium entry in rat olfactory bulb granule cells. Eur J Neurosci 27:2066-2075.

Egger V, Stroh O (2009) Calcium buffering in rodent olfactory bulb granule cells and mitral cells. J Physiol 587:4467-4479.

Egger V, Svoboda K, Mainen ZF (2003) Mechanisms of lateral inhibition in the olfactory bulb: efficiency and modulation of spike-evoked calcium influx into granule cells. J Neurosci 23:7551-7558.

Egger V, Svoboda K, Mainen ZF (2005) Dendrodendritic synaptic signals in olfactory bulb granule cells: local spine boost and global low-threshold spike. J Neurosci 25:3521-3530.

El-Hassar L, Hagenston AM, D’Angelo LB, Yeckel MF (2011) Metabotropic glutamate receptors regulate hippocampal CA1 pyramidal neuron excitability via $\mathrm{Ca}^{2+}$ wave-dependent activation of SK and TRPC channels. J Physiol 589:3211-3229.

Fowler MA, Sidiropoulou K, Ozkan ED, Phillips CW, Cooper DC (2007) Corticolimbic expression of TRPC4 and TRPC5 channels in the rodent brain. PLoS One 2:e573.

Freichel M, Suh SH, Pfeifer A, Schweig U, Trost C, Weissgerber P, Biel M,
Philipp S, Freise D, Droogmans G, Hofmann F, Flockerzi V, Nilius B (2001) Lack of an endothelial store-operated $\mathrm{Ca}^{2+}$ current impairs agonist-dependent vasorelaxation in $\mathrm{TRP}^{-1-}$ mice. Nat Cell Biol 3:121-127.

Fukunaga I, Yeo CH, Batchelor AM (2007) Potent and specific action of the mGlul antagonists YM-298198 and JNJ16259685 on synaptic transmission in rat cerebellar slices. Br J Pharmacol 151:870-876.

Gervásio OL, Whitehead NP, Yeung EW, Phillips WD, Allen DG (2008) TRPC1 binds to caveolin-3 and is regulated by Src kinase-role in Duchenne muscular dystrophy. J Cell Sci 121:2246-2255.

Ghatpande AS, Gelperin A (2009) Presynaptic muscarinic receptors enhance glutamate release at the mitral/tufted to granule cell dendrodendritic synapse in the rat main olfactory bulb. J Neurophysiol 101:2052-2061.

Glitsch MD (2010) Activation of native TRPC3 cation channels by phospholipase D. FASEB J 24:318-325.

Goel M, Sinkins WG, Schilling WP (2002) Selective association of TRPC channel subunits in rat brain synaptosomes. J Biol Chem 277:48303-48310.

Halabisky B, Friedman D, Radojicic M, Strowbridge BW (2000) Calcium influx through NMDA receptors directly evokes GABA release in olfactory bulb granule cells. J Neurosci 20:5124-5134.

Hall BJ, Delaney KR (2002) Contribution of a calcium-activated nonspecific conductance to NMDA receptor-mediated synaptic potentials in granule cells of the frog olfactory bulb. J Physiol 543:819-834.

Hartmann J, Dragicevic E, Adelsberger H, Henning HA, Sumser M, Abramowitz J, Blum R, Dietrich A, Freichel M, Flockerzi V, Birnbaumer L, Konnerth A (2008) TRPC3 channels are required for synaptic transmission and motor coordination. Neuron 59:392-398.

Hartmann J, Henning HA, Konnerth A (2011) mGluR1/TRPC3-mediated synaptic transmission and calcium signaling in mammalian central neurons. Cold Spring Harb Perspect Biol 3:pii:a006726.

Head BP, Patel HH, Tsutsumi YM, Hu Y, Mejia T, Mora RC, Insel PA, Roth DM, Drummond JC, Patel PM (2008) Caveolin-1 expression is essential for $N$-methyl-D-aspartate receptor-mediated Src and extracellular signalregulated kinase 1/2 activation and protection of primary neurons from ischemic cell death. FASEB J 22:828-840.

Heinbockel T, Laaris N, Ennis M (2007) Metabotropic glutamate receptors in the main olfactory bulb drive granule cell-mediated inhibition. J Neurophysiol 97:858-870.

Hofmann T, Schaefer M, Schultz G, Gudermann T (2002) Subunit composition of mammalian transient receptor potential channels in living cells. Proc Natl Acad Sci U S A 99:7461-7466.

Horne EA, Dell'Acqua ML (2007) Phospholipase C is required for changes in postsynaptic structure and function associated with NMDA receptordependent long-term depression. J Neurosci 27:3523-3534.

Isaacson JS (1999) Glutamate spillover mediates excitatory transmission in the rat olfactory bulb. Neuron 23:377-384.

Isaacson JS (2001) Mechanisms governing dendritic gamma-aminobutyric acid (GABA) release in the rat olfactory bulb. Proc Natl Acad Sci U S A 98:337-342.

Isaacson JS, Strowbridge BW (1998) Olfactory reciprocal synapses: dendritic signaling in the CNS. Neuron 20:749-761.

Jahr CE, Nicoll RA (1980) Dendrodendritic inhibition: demonstration with intracellular recording. Science 207:1473-1475.

Kapoor V, Urban NN (2006) Glomerulus-specific, long-latency activity in the olfactory bulb granule cell network. J Neurosci 26:11706-11719.

Kim SJ, Kim YS, Yuan JP, Petralia RS, Worley PF, Linden DJ (2003) Activation of the TRPC1 cation channel by metabotropic glutamate receptor mGluR1. Nature 426:285-291.

Laaris N, Puche A, Ennis M (2007) Complementary postsynaptic activity patterns elicited in olfactory bulb by stimulation of mitral/tufted and centrifugal fiber inputs to granule cells. J Neurophysiol 97:296-306.

Lein ES, Hawrylycz MJ, Ao N, Ayres M, Bensinger A, Bernard A, Boe AF, Boguski MS, Brockway KS, Byrnes EJ, Chen L, Chen L, Chen TM, Chin MC, Chong J, Crook BE, Czaplinska A, Dang CN, Datta S, Dee NR, et al. (2007) Genome-wide atlas of gene expression in the adult mouse brain. Nature 445:168-176.

Lisman J, Spruston N (2010) Questions about STDP as a general model of synaptic plasticity. Front Synaptic Neurosci 2:140.

Lockwich TP, Liu X, Singh BB, Jadlowiec J, Weiland S, Ambudkar IS (2000) 
Assembly of Trp1 in a signaling complex associated with caveolinscaffolding lipid raft domains. J Biol Chem 275:11934-11942.

Lübke J, Egger V, Sakmann B, Feldmeyer D (2000) Columnar organization of dendrites and axons of single and synaptically coupled excitatory spiny neurons in layer 4 of the rat barrel cortex. J Neurosci 20:5300-5311.

Macrides F, Chorover SL (1972) Olfactory bulb units: activity correlated with inhalation cycles and odor quality. Science 175:84-87.

Moran MM, Xu H, Clapham DE (2004) TRP ion channels in the nervous system. Curr Opin Neurobiol 14:362-369.

Munsch T, Freichel M, Flockerzi V, Pape HC (2003) Contribution of transient receptor potential channels to the control of GABA release from dendrites. Proc Natl Acad Sci U S A 100:16065-16070.

Odell AF, Scott JL, Van Helden DF (2005) Epidermal growth factor induces tyrosine phosphorylation, membrane insertion, and activation of transient receptor potential channel 4. J Biol Chem 280:37974-37987.

Orona E, Scott JW, Rainer EC (1983) Different granule cell populations innervate superficial and deep regions of the external plexiform layer in rat olfactory bulb. J Comp Neurol 217:227-237.

Pace RW, Mackay DD, Feldman JL, Del Negro CA (2007) Inspiratory bursts in the preBotzinger complex depend on a calcium-activated non-specific cation current linked to glutamate receptors in neonatal mice. J Physiol 582:113-125.

Pinato G, Midtgaard J (2003) Regulation of granule cell excitability by a low-threshold calcium spike in turtle olfactory bulb. J Neurophysiol 90:3341-3351.

Pressler RT, Inoue T, Strowbridge BW (2007) Muscarinic receptor activation modulates granule cell excitability and potentiates inhibition onto mitral cells in the rat olfactory bulb. J Neurosci 27:10969-10981.

Riccio A, Li Y, Moon J, Kim KS, Smith KS, Rudolph U, Gapon S, Yao GL, Tsvetkov E, Rodig SJ, Van't Veer A, Meloni EG, Carlezon WA Jr, Bolshakov VY, Clapham DE (2009) Essential role for TRPC5 in amygdala function and fear-related behavior. Cell 137:761-772.

Salin PA, Lledo PM, Vincent JD, Charpak S (2001) Dendritic glutamate autoreceptors modulate signal processing in rat mitral cells. J Neurophysiol 85:1275-1282.

Schoppa NE, Westbrook GL (1999) Regulation of synaptic timing in the olfactory bulb by an A-type potassium current. Nat Neurosci 2:11061113.

Schoppa NE, Kinzie JM, Sahara Y, Segerson TP, Westbrook GL (1998) Den- drodendritic inhibition in the olfactory bulb is driven by NMDA receptors. J Neurosci 18:6790-6802.

Shepherd GM, Greer CA (2004) Olfactory bulb. In: The synaptic organization of the brain, Ed 3 (Shepherd GM, ed), pp 133-169. New York: Oxford UP.

Soboloff J, Spassova M, Hewavitharana T, He LP, Luncsford P, Xu W, Venkatachalam K, van Rossum D, Patterson RL, Gill DL (2007) TRPC channels: integrators of multiple cellular signals. Handb Exp Pharmacol 2007:575-591.

Strübing C, Krapivinsky G, Krapivinsky L, Clapham DE (2001) TRPC1 and TRPC5 form a novel cation channel in mammalian brain. Neuron 29:645-655.

Topolnik L, Azzi M, Morin F, Kougioumoutzakis A, Lacaille JC (2006) mGluR1/5 subtype-specific calcium signalling and induction of longterm potentiation in rat hippocampal oriens/alveus interneurones. J Physiol 575:115-131.

Wu LJ, Sweet TB, Clapham DE (2010) International Union of Basic and Clinical Pharmacology. LXXVI. Current progress in the mammalian TRP ion channel family. Pharmacol Rev 62:381-404.

Xue T, Do MT, Riccio A, Jiang Z, Hsieh J, Wang HC, Merbs SL, Welsbie DS, Yoshioka T, Weissgerber P, Stolz S, Flockerzi V, Freichel M, Simon MI, Clapham DE, Yau KW (2011) Melanopsin signalling in mammalian iris and retina. Nature 479:67-73.

Zechel S, Werner S, von Bohlen und Halbach O (2007) Distribution of TRPC4 in developing and adult murine brain. Cell Tissue Res 328: 651-656.

Zelles T, Boyd JD, Hardy AB, Delaney KR (2006) Branch-specific $\mathrm{Ca}^{2+}$ influx from $\mathrm{Na}^{+}$-dependent dendritic spikes in olfactory granule cells. J Neurosci 26:30-40.

Zhang Z, Reboreda A, Alonso A, Barker PA, Séguéla P (2011) TRPC channels underlie cholinergic plateau potentials and persistent activity in entorhinal cortex. Hippocampus 21:386-397.

Zheng N, Raman IM (2011) Prolonged postinhibitory rebound firing in the cerebellar nuclei mediated by group I metabotropic glutamate receptor potentiation of L-type calcium currents. J Neurosci 31:10283-10292.

Zhu MX (2005) Multiple roles of calmodulin and other $\mathrm{Ca}^{2+}$-binding proteins in the functional regulation of TRP channels. Pflugers Arch 451: $105-115$.

Zufall F, Ukhanov K, Lucas P, Liman ER, Leinders-Zufall T (2005) Neurobiology of TRPC2: from gene to behavior. Pflugers Arch 451:61-71. 